\title{
Quality and integrity in scientific writing: prerequisites for quality in science communication
}

\author{
Marie-Claude Roland
}

\begin{abstract}
Standards and Good Practice guidelines provide explicit criteria for maintaining quality and integrity in science. But research practices are now openly questioned. I defend the idea that the tension between norms and practices in scientific writing must be addressed primarily by the scientific community if quality of the sources in the process of science communication is to be guaranteed. This paper provides evidence that scientific writing and researchers'writing practices do not reflect expected quality criteria. Evidence is based on four complementary analyses of: (i) communication manuals, journals' recommendations to authors and the norms they convey (ii) feedback given by reviewers (ii) interviews and questionnaires (iv) researchers' written productions and writing practices. I show that researchers' writing and communication practices are very often in total contradiction with the norms and standards the scientific community has established. Unless researchers can improve and guarantee quality and integrity of the sources, the whole system of science communication will be threatened.
\end{abstract}

\section{Introduction}

On the end of the $19^{\text {th }}$ century, Jane Gregory and Steve Miller write: "a gulf opened between the science communication that was felt to be appropriate between scientists and the popularization that the public could appreciate $(\ldots)$ And the $20^{\text {th }}$ century then sees scientific communication divided - between disciplines within science, and between science and the public". ${ }^{1}$ Scientists progressively withdrew into their scientific communities as various professional groups took over, popularizing science according to their own objectives and using a large range of media. Inevitably, the challenge would be to ensure the quality and credibility of the information used to inform the public and make decisions, and first of all to ensure that the sources - i.e. primary articles - are not "polluted" to prevent contamination downstream.

Here, I want to focus on scientific writing, i.e. scientific papers and researchers' writing practices to provide evidence that they do not reflect expected quality criteria, arguing that all the communicative changes linked to economic and social changes in the scientific community since the end of the $19^{\text {th }}$ century have changed the image of researchers: they now appear as shunning responsibility, being just tentative, too polite to criticize research by others, eventually relying on writing practices that verge on fraud. ${ }^{2}$ Gross $\&$ al. argue that "the facts (they) have amassed concerning communicative and argumentative practices in science support the hypothesis that current practices are a consequence of the selective survival of practices that were, persistently, better adapted to the changing environment of the various scientific disciplines over time". Hence they conclude that the changes observed in the presentation and organization of scientific articles are in the interest of communicative efficiency.

In line with the previous statements I have made, I am suggesting here that the very features that according to Gross et al. promote efficiency in reading, do not guarantee effective, reliable, quality communication among researchers because of the conformism and deviant behaviours inherent to a system of reproduction; ${ }^{4}$ I further suggest that they are major obstacles to quality communication with other interacting players in the process of science communication and therefore raise the following questions about the future of scientific articles: does the "knowledge-manufacturing machine of the $20^{\text {th }}$ century" ensure quality of its products- or just purposeful productivity and communicative efficiency for an ever restricted audience? In other words, can researchers still ensure quality and integrity of the primary sources in the process of science communication? 
Such questions are crucial in the present context: firstly, more and more journalists are going to the sources - primary papers- even before they are actually published. Secondly, the role played by "intermediaries" in the process of science communication has been growing, but the profession of "science communicators" itself includes many different actors with various professional skills and practices and different aims - from professors in universities "doing research and talking about", or teaching "science communication" within university programmes, to consultants "helping researchers in distress", to science festival organizers, etc. Thirdly, researchers are now urged to communicate directly to the public and in a different way: talking honestly about their research to a public who can understand them and is more and more eager to participate in the research process. ${ }^{5}$

\section{Society puts the burden on the shoulders of researchers}

If we take a brief look at history, until the $20^{\text {th }}$ century, science stories had been written mostly by scientists. Then scientists withdrew into their own community, and particular professional groups took over - scientific organizations, commercial publishers, the government, science writers-, each group reporting about science with their own interests, objectives and strategy and using different media. What should have been a primary and essential concern - how to guarantee quality and integrity in the information chain to ensure that the public receives the most scientifically strong product through a credible process- was perhaps too much overlooked and authors of scientific papers (the sources) have not been wary enough to ensure that their papers would be easily read and properly understood by those whose job is to write stories about or built on the findings reported. The gap between researchers and other professional groups has been widening, and for several years now voices in the movement for "public understanding of science" and in the debate about science and its role in society have been calling for a cultural change in the scientific community: researchers are urged to better communicate, interact with the public and all the popularizers of science and to develop their communication skills.

As a recent Eurobarometer survey shows, the burden is now clearly on the shoulders of the researchers for two main reasons: ease of understanding and reliability. ${ }^{6}$

"Science is regarded as a matter for scientists: the majority of EU citizens would prefer to restrict public scientific debates to scientists rather than actively participate themselves; they also prefer that scientists rather than journalists present scientific information. Thus we can infer that Europeans have little doubt about the ability of experts to explain scientific information clearly. On the other hand, those preferring that journalists present scientific information stress that this would make it easier to understand." (page 60). Indeed $49 \%$ of people found information provided by media on scientific research difficult to understand, while journalists and broadcasters themselves confess having some difficulty in understanding science and scientists.

The Eurobarometer study also concludes that "Europeans would prefer scientists rather than journalists to present scientific information in the media as they consider this would be more trustworthy and more precise." (page 59).

\section{Writing practices within the scientific community will not make it easy for researchers to improve quality of primary communication}

Achieving ease of understanding and reliability will be major challenges for researchers: the studies I have conducted clearly show that researchers' writing practices and their products (primary papers and other documents) very often do not conform to quality criteria: I found that although official bodies within the scientific community regularly publish recommendations to authors or good practice guidelines, a majority of researchers tend to ignore them and conform to the model that circulates within their communities. ${ }^{7}$ Then, the review process which is an integral part of what I call researchers' writing practices, obviously does not play its role in maintaining quality and integrity of the sources. ${ }^{8}$

Quality in scientific writing is defined through norms and standards officially released by national standard institutions (American National Standard Institute's Standards for the Preparation of Scientific Papers for written and oral presentation and for Writing Abstracts, Norme pour la rédaction de résumés et d'articles, Agence Française de Normalisation). ${ }^{9,10}$ In 1978, the Vancouver Group worked to establish guidelines for the format of manuscripts submitted to their journals, leading to the formulation of clear 
rules for good writing and communication practices, including ethics. ${ }^{11}$ Manuals and journals stepped in to promote explicit communicative norms with only slight variations depending on the specificities of the disciplines or domains. A number of quality indicators can be identified from existing documents: they address quality both in the doing of science and in its communication, since "Science exists because scientists are writers and speakers.(...) As a form of knowledge, scientific understanding is inseparable from the written and spoken word. There are no boundaries, no walls between the doing of science and the communication of it, communicating is the doing of science". ${ }^{12}$

Quality in research must be found at three levels: at the level of initial objectives validated, at the level of process and at the level of results. Significance is about quality in the formulation of the problem, the readability of the aims to be achieved, the degree of scientific challenge and is associated with originality, scientific interest, relevance and clarity. "I believe that the key to scientific writing is clarity. Successful scientific experimentation is the result of a clear mind attacking a clearly stated problem and producing clearly stated conclusions. Ideally, clarity should be a characteristic of any type of communication." 13 Rigour is about quality of the design, of the argumentation, about overall coherence, traceability and reliability of the sources as well as of the results. Integrity cuts across all three levels of quality. As for quality of the scientific style, the criteria are very clear: "Good scientific writing is logical, clear, precise, direct, and concise. Its main scientific quality lies in precision, and all words should therefore be used in an exact sense. If the sense intended is different from that commonly understood or defined in dictionaries, the usage should be carefully explained. The same principle applies to terms used colloquially by a small group of investigators; (...) the language used should be as simple as is compatible with the subject and as concise as is compatible with ready understanding. An extremely terse style, which can be cryptic, is as much a barrier to communication as is verbosity." ${ }^{14}$ All the authors of scientific writing manuals warn their readers about common pitfalls and advise them to avoid excessive use of the passive voice which leads to ambiguity, confusion, dullness and distorted meaning, and to prefer the active voice, a sign that the writer is honest and takes responsibility for his statements; to restrict use of long clusters of words which include many different modifiers: non specialists will not be able to understand them and even specialists may be lead into error; to minimize the use of stereotyped patterns of expressions which strait-jacket ideas. ${ }^{15,16,17}$

So much for principles. What are actual practices? Reading Georges Pérec's admirable- and hilarious pastiche of the scientific article entitled "Experimental Demonstration of the tomatotopic organization in the soprano (Cantatrix sopranica L.)" provides a shocking answer. ${ }^{18}$ The short abstract is a gem - it contains all the indicators of poor quality writing -, while the introduction is a catalogue of the most exotic references, rather than a strong construction of background elements chosen for their relevance to a clearly stated scientific problem. As part of my research, I compared actual writing practices with the norms established by the scientific community and came to the conclusion that most of the papers pointed to a contradiction between the norms and the practices, in other words that quality criteria were not complied with. ${ }^{19}$ I analysed the contents of over two hundred reports from reviewers, obtained from researchers, and dozens of scientific writing manuals and recommendations to authors from various journals, to verify that the criteria for good scientific writing the authors of manuals and the reviewers were using reflected the norms. I analyzed several hundreds of papers - both accepted and rejected ones from a large range of journals and disciplines, checking them at two levels: coherence and rigour of scientific content, and style. I focused mainly on the abstract, the introduction and the discussion which I assume are the key sections in the scientific article where the competences of the researcher and the quality of the writing are most likely to be found. My analysis was based on the following questions, while I looked for all relevant linguistic traits and occurrences and also for any personal involvement of the author (use of the personal form, quality of the modifiers etc): (i) Does the paper convey a clear message? What is the structure and content of the title? (ii) Is the scientific problem clearly formulated? Does the author just list facts, juxtaposes statements or is the problem constructed? (iii) Can I identify a clearly stated hypothesis or research question the authors want to address in the paper? Is the personal contribution to existing knowledge easy to locate? (iv) What are the relationships between problem and specific question or hypothesis? Are those relations explicit? (v) Has the author seen the interest of his/her work? How does he /she relate his/her findings to those of other authors? Are the comparisons relevant and meaningful? (vi) How does the author formulate his/her own hypotheses? Are they easily distinguished from those existing in the literature? Does he/she over-speculate?

My main findings, for both accepted and rejected papers, can be summarized as follows: $:^{20,21,22}$ (i) In the abstract, introduction and discussion, authors are reluctant to use the personal form. Therefore it is 
extremely difficult for the reader to identify with certainty the hypothesis or the specific question the author is addressing in the paper or suggesting in the discussion. I noted very few occurrences of expressions like "we hypothesized" or "the specific question we want to address". Authors prefer to use very vague formulae pointing to a gap in knowledge - "very little is known about..." - or to potential/putative influence/impact/role of A on B - which do not make the hypothesis explicit. Similarly, in the discussion, it is very difficult to distinguish between hypotheses from the literature and the author's own hypothesis: even when speculating, the author hides behind the impersonal (ii) Hedging, which is a distinctive feature of scientific writing and a resource in what can be called tribal communication among researchers, ${ }^{23}$ is abused in the three sections I considered, authors use a plethora of modifiers, the most common being "may" which in itself means 'I don't know' and leaves equal chances for a statement to be true or not. (iii) In all three sections, as well as in the title, authors use long strings of nouns - known as noun clusters, stacked modifiers or fused noun strings-, later turned into acronyms. This remarkable resource of the English language implies that all kinds of relationships between the different modifiers have disappeared and that only a specialist of the domain is likely to understand for instance, what "a multi-domain wavelength division multiplexed (WDM) network structure for reconfigurable partitionable massively parallel computer architecture" refers to. (iv) The introduction follows a very descriptive model in which elements of the research are literally introduced to the reader, i.e. presented as a long catalogue of definitions, an accumulation of facts or observations supported by references, reminiscent of an encyclopaedic presentation. The information is not processed by the authors to make the problem addressed clear from the start. The aim of the paper is usually announced at the very end of the introduction - typically the last three or four lines- and it is very often either technical or very vague: verbs found in the key phrase "the objective/aim of the paper is to" can be related to methods- measure, analyse, test, develop (a model, a scenario, a tool, a procedure) - or they are imprecise - to explore various (parameters, designs, etc), to provide (quantitative, qualitative) information about, to study the role/impact of, to try to establish relations between, to find new (criteria, tools, relations) etc. (v) Both introduction and discussion are not structured in well designed paragraphs to deliver information unambiguously: topic sentences and topical structure are seldom used, and repetitions of the theme within the same paragraph are abundant. The introduction and the discussion are "rambling", i.e. not structured to give a demonstration and build strong argumentation, with over-use of links like "however, besides, nevertheless, moreover" which point to accumulation and backand forth movements in the thinking process.

Describing the evolution of presentation and organization of the scientific article in the second half of the $20^{\text {th }}$ century in a context of hyperspecialization and mass production of scientific articles, Gross et al. confirm that prominent features include "the passive voice and the dummy subject to keep the prose objective", hedging and impersonal expression. ${ }^{24}$ They also note that "the deployment of specialized literary devices (fused noun strings, abbreviations, etc) (are) aimed at compactly conveying technical messages to small groups of highly trained readers in a specialized research field" and that "the scientific prose is challenging to grasp for the uninitiated" and demand "serious decoding abilities on the part of readers". They proceed to show that "all these measures (i.e. use of personal pronouns, evaluative expression, metaphors and similes) were on a generally downward slide during the $20^{\text {th }}$ century, as technical language and painstaking description have largely elbowed out what little personal language remained at the turn of the century", emphasizing that the balance between the two narrative planes described by Latour - one in which the narrator is active, the other in which the action is delegated to a nonhuman one - has steadily drifted to the nonhuman one. ${ }^{25}$ Montgomery also confirms that "Any point at which there emerges something resembling a truly personal or literary style in a technical article is commonly considered to be a point of failure". ${ }^{26}$

Questioning quality and integrity in scientific writing, I want to emphasize that these features in fact show that authors are not committed to their writing and forget about their readers, allowing them to construct the meaning according to their own background knowledge and expectations, which paves the way for interpretations, reconstructions and, as I already explained, to fraud. ${ }^{27}$ I want also to highlight the fact that I found these features both in published and rejected papers - which leads to questioning the reliability of the review process in maintaining quality. 


\section{Maintaining quality in scientific writing: have scientists been doing all that well?}

Literature and experience reveal that, again, actual practices do not match the good practice principles established and set as an objective to researchers by scientific institutions and funding bodies.

Peer review is one of the important procedures used to ensure that the quality of published information meets the standards of the scientific and technical community, the results of peer review being one key criteria used to make decisions about journal publication, grant funding and information dissemination. Briefly, the peer reviewer's report is an evaluation or critique that is used by the authors of the draft to improve the product. Peer review typically evaluates the clarity of hypotheses, the validity of the research design, the quality of data collection procedures, the robustness of the methods employed, the appropriateness of the methods for the hypotheses being tested, the extent to which the conclusions follow from the analysis, and the strengths and limitations of the overall product. Secondly, the selection of participants in a peer review is based on expertise, with independence and conflict of interests taken in due consideration.

So much for principles. What are actual practices? The capacity of peer reviewing to develop and ensure quality communication is widely questioned. L. P Schmelkin exposes "a litany of flaws and problems" that plague the review process, described as "prone to bias", "yielding papers that are grossly flawed", "sloppy", "subjective", "having many reviewers who are incompetent", "stifling scientific communication and hence slowing the advancement of knowledge"- just to quote a few. ${ }^{28}$

Because researchers who write papers are the same who eventually review their colleagues' papers, I will briefly focus on two major problems I have repeatedly encountered and tried to solve with researchers: one is their interactions with reviewers; the second is their critical reading competence on which their critical writing abilities depend. For many authors, submitting a manuscript is a one-way process in which they forget to take responsibility for how they communicate and how their message is received: how many times have I listened to the same frustration when a paper is not accepted: "I can't be held responsible for how they interpret what I say / the reviewers have missed the point / I am just another victim in the system of competition or power relationships, etc". As Agarwal et al. and Seibert remark, while feedback should play an essential role in communication between authors and reviewers, most of the time the review process does not seem to benefit the authors as it could. ${ }^{29,30}$ Authors do not seem to take reviewers seriously and to be willing to engage in constructive interactions with them. "If writing is the highest form of thinking, then the review process may be one of the most challenging but rewarding experiences of your academic life" insists Seibert; and he concludes that "authors should therefore approach their replies to R\&Rs as a matter of their own ongoing education and discovery process - not as an effort to justify their own particular approach or gloss over weaknesses of their methods or data.". ${ }^{31}$ Evidence also suggests that the major problem with peer review is lack of critical assessment skills, which is one of the fundamentals of scientific writing. ${ }^{32}$ Researchers tend to read primarily for information and not for ways of thinking about the subject matter or the kinds of reasoning the text reveals. They tend to isolate facts, examples, looking for the information they expect to find. Critical reading involves evaluation of how a text is argued, assessment of the strengths and weaknesses of the arguments.

Many questions can be therefore be raised, here are a few: can researchers accept to dialogue with their peers? can they become learners in the review process? do researchers who are recruited as reviewers have the competencies required to conduct evaluation - especially the linguistic competencies? are they not likely to reinforce a system which has overlooked quality under the pressure of the "Publish or Perish" mantra? Can someone just fresh from a PhD be considered as an effective reviewer? (Yet this is what is happening more and more).

\section{Rethinking the training of researchers to defend quality of scientific writing}

« First warn your students not to aim for the currently accepted style of scientific writing. They should not study the leading journal in their specialty and attempt to imitate the writing it contains": Robert Day was warning his readers about "the ritualistic mode of expression" revered by many scientists, "grandiose and alien to science's grand purpose - which is surely explanation, not obfuscation". ${ }^{33}$ Day's voice has not been heard in the tumultuous competition of the past decades. Several trends that affect the scientific community can explain the present situation. ${ }^{34}$ I will focus here on two major findings obtained from a 
study on the representations researchers have of their relation with writing and their writing practices, and from a series of tests of linguistic competence proposed to over 300 junior and senior researchers from various disciplinary backgrounds and institutions. ${ }^{35}$ The first study included both interviews and a questionnaire focused on the following questions: (i) do you like/enjoy writing? (ii) How do you rate the importance of writing in your professional career? (iii) Do you experience difficulties in writing? (iv) Which strategies do you use to overcome these difficulties? (v) How many scientific articles do you read per week? (v) Apart from scientific papers, do you read other documents - books, newspapers, magazines? (vi) Describe your purpose when reading and the way you read (vii) Describe your strategy for writing a scientific paper (viii) Have you received specific training for writing scientific papers? (ix) How do you evaluate your students' writing? (x) do you think your students are receiving adequate training in order to become effective writers? The main results are the following: although writing is perceived as an absolute necessity in their profession and although it may occupy as much as $60 \%$ of their time, a vast majority of respondents say they do not like writing. A minority though enjoys writing personal letters or keeping diaries. Organizing one's ideas clearly and constructing effective paragraphs are among the major difficulties encountered when writing, followed by use of tenses and modals, linking sentences effectively, especially in the discussion section of a paper. The most common tool used to overcome those difficulties is a dictionary. A lot of researchers may also buy the services of translators or native speakers. A majority of respondents read only scientific papers of their domain - which keeps them very busy and leaves no time for reading books or newspapers. Their reading practices vary; an overwhelming majority starts with the abstract and then will look for information in the different sections of the paper, very often focusing first on tables, graphs and figures. They will read an article thoroughly only if it is "interesting". Regarding training, more than $90 \%$ of the researchers surveyed say they have not been properly trained to become scientific writers and that their students are not well prepared either. The tests of linguistic competence included both a multiple choice questionnaire (MCQ) designed to verify use of tenses, modals, syntactic constructions and terminology, and a test of style in which researchers were asked to assess the quality of sentences found in papers with which they were familiar, to explain their reasoning behind assessment and eventually to correct the sentences if they wished to do so. Results lead to two main conclusions: first, there was little coherence in answers to the MCQ; second, the critical assessment skills displayed were on the whole quite low. The majority of the researchers felt quite comfortable with the usual scientific style.

\section{Conclusion}

Researchers, because they are authors and reviewers of scientific papers which are the sources that feed the channels of science communication, are responsible for quality in the first place: they are being warned against FFPs (Fabrication, Falsification and Plagiarism) and QRPs (Questionable Research Practices). I am asking, what about QCPs - Questionable Communication Practices? Quality communication will not be achieved without thoroughly rethinking current practices and training in the scientific community. Researchers have forgotten that "science communication is a two-way process. (...) A published scientific paper is useless unless it is both received and understood by its intended audience". ${ }^{36}$ They have also forgotten that "Learning how to report results should not be separated from learning how to get results". ${ }^{37}$ With the development of the Open Access initiative, which is making an unprecedented public good possible, the academic communication system must be reconsidered. I will borrow the final word from Lawrence and Locke who admit that "Clocks cannot be turned back. But pendulums can swing and we hope that they will start to swing soon in the matters we raise here."

\section{Notes and references}

\footnotetext{
1 J. Gregory and S. Miller (1998), Science in Public, Basic Books (1998), page 26.

M.C. Roland (2007), Publish and Perish: hedging and fraud in scientific discourse, EMBO reports vol. 8 n. 5.

3 A.G. Gross, J.E. Harmon and M. Reidy (2002), Communicating Science, The Scientific Article from the $17^{\text {th }}$ Century to the Present, Oxford University Press.

4 See note 2 .
} 
5 European Commission (2008), EUR 23334 - Public Engagement in Science, Luxembourg: Office for Official Publications of the European Communities, 60 pp.

${ }^{6}$ Directorate-General for Research, European Commission (2007), Scientific research in the Media, Special Eurobarometer282/Wave67.2, TNS Opinion \& Social.

7 M.C. Roland (1995), Analysis of researchers' writing practices, PhD Thesis, University of Grenoble III, France (the thesis can be accessed at www.reflexives-lpr.org).

8 L.P. Schmelkin (2003), Peer review: Standard or delusion?, Division 5 Presidential Address delivered at the annual meeting of the American Psychological Association, Toronto, Aug. 2003.

9 American National Standard Institute (1979), American National Standard for Writing abstracts, ANSI Z 39, 14-1979;

American National Standard for the Preparation of Scientific Papers for written and oral presentation, ANSI Z 39, 16-1979

${ }^{10}$ Association Française de Normalisation (AFNOR) (2001), Démarche Qualité en recherche: principes généraux et recommandations, Indice de classement X50-550.

${ }^{11}$ International Committee of Medical Journal Editors (ICMJE) (1978), Uniform Requirements for Manuscripts Submitted to Biomedical Journals: Writing and Editing for Biomedical Publication, Updated October 2007, http://www.icmje.org/.

${ }^{12}$ S.L. Montgomery (2003), The Chicago Guide to Communicating Science, The University of Chicago Press.

${ }^{13}$ R. Day (1991), How to write publish a scientific paper, $3^{\text {rd }}$ edition, Cambridge University Press.

${ }^{14}$ See note 9.

${ }^{15}$ See note 9 .

${ }^{16}$ See note 12 .

${ }^{17}$ M. Young (1991), The Technical Writer's Handbook, University Science Books, Mill Valley CA.

${ }^{18}$ G. Pérec (1980), Experimental Demonstration of the tomatotopic organization in the soprano (Cantatrix sopranica L.), first published in Banana Split n², June 1980, available in SubStance 9(29), No. 4: 37-45, University of Wisconsin Press.

${ }^{19}$ See note 7.

${ }^{20}$ See note 7 .

${ }^{21}$ M.C. Roland (2006), The Changing Paradigm of Science Communication: Challenges for researchers, From a "deficit" model to a "democratic" model in Claessens M (under the direction of) CER 2005 Proceedings, Springer.

${ }^{22}$ See note 2 .

${ }^{23}$ K. Hyland (1998), Hedging in Scientific Articles, Pragmatic \& Beyond New Series, John Bejamins Publishing Company.

${ }^{24}$ See note 3 , chapter 8 .

${ }^{25}$ See note 3, pp 166-169.

${ }^{26}$ See note 12 .

${ }^{27}$ See note 2.

${ }^{28}$ See note 8 .

${ }^{29}$ R. Agarwal, R. Echambadi, A.M. Franco and M.B. Sarkhar (2006), Reap rewards: maximising benefits from reviewer comments, Academy of Management Journal 49(2): 191-195.

${ }^{30}$ S.E. Seibert (2006), Anatomy of an R\&R (or, Reviewers are an Author's Best Friends...), Academy of Management Journal 49(2): 203-207.

${ }^{31}$ See note 30 , page 205 .

${ }^{32}$ F. Davidoff (1998), Masking, blinding, and peer review: The blind leading the blinded, Ann Intern Med, 128: 66-8.

${ }^{33}$ See note 13 .

${ }^{34}$ See note 21

${ }^{35}$ See note 7.

${ }^{36}$ See note 13

${ }^{37}$ P.A. Lawrence and M. Locke (1997), A man for our season, Nature 386, 757.

\section{Author}

Marie-Claude Roland, $\mathrm{PhD}$, is the Director of a research-action project (Linguistics \& Research Practices) at the French National Institute for Agricultural Research (INRA). The project is based on the results of her $\mathrm{PhD}$ research (1995). With a team of thirty researchers who are actively involved as facilitators, she has developed a training programme for PhD students and senior researchers to convince them that dialogue and reflective practice are necessary to address the issues of quality and integrity.

E-mail: marie-claude.roland@wanadoo.fr.

HOW TO CITE: $\quad$ M.C. Roland, Quality and integrity in scientific writing: prerequisites for quality in science communication, Jcom 08(02) (2009) A04. 